Check for updates

Cite this: RSC Adv., 2019, 9, 23

Received 11th November 2018 Accepted 10th December 2018

DOI: $10.1039 / c 8 \mathrm{ra09303b}$

rsc.li/rsc-advances

\section{Tetra-fluorinated aromatic azide for highly efficient bioconjugation in living cells $\uparrow$}

\author{
Xuekang Cai,,$^{\text {ab }}$ Dan Wang,,$^{\mathrm{c}}$ Yasi Gao, ${ }^{\mathrm{b}}$ Long Yi, (D) ${ }^{\text {bd }}$ Xing Yang (D) *ae and Zhen Xi*cd
}

We developed a fast strain-promoted azide-alkyne cycloaddition reaction (SPAAC) by tetra-fluorinated aromatic azide with a kinetic constant of $3.60 \mathrm{M}^{-1} \mathrm{~s}^{-1}$, which is among the fastest SPAAC ligations reported so far. We successfully employed the reaction for covalent labelling of proteins with high efficiency and for bioimaging of mitochondria in living cells. The reaction could be a generally useful toolbox for chemical biology and biomaterials.
Strain-promoted azide-alkyne cycloaddition (SPAAC) as an efficient bioconjugation tool has recently found a wide range of applications in chemical biology, materials science and medical science..$^{1-3}$ In 2001, Sharpless et al., first introduced the concept of click chemistry that emphasized on the rapid synthesis of useful new compounds and combinatorial libraries through heteroatom links $(\mathrm{C}-\mathrm{X}-\mathrm{C}){ }^{4}$ To overcome the limitations for classical copper-catalyzed azide-alkyne cycloaddition (CuAAC), ${ }^{5}$ Bertozzi improved the method using strained cyclooctynes to react with azide in 2004, which effectively avoids the transition metal catalysts (such as $\mathrm{Cu}$ ) and makes it more general for bioconjugations. ${ }^{6,7}$ It gave birth to the development of SPAAC. But one of the limitations is the relative low reaction rate compared with other biorthogonal reactions and a high rate could be beneficial for labelling low abundance or transient structures with short-lived signal molecules, such as radioisotopes for imaging. ${ }^{8}$ During the past decade, efforts have been made to further improve the method. Structure modified cyclooctynes, including aliphatic cyclooctynes ${ }^{9}$ and (di)benzoannulated cyclooctynes ${ }^{10}$ have been investigated to accelerate the reaction, and recently the modified azides was also reported to remarkably increase SPAAC rate. ${ }^{11}$

\footnotetext{
${ }^{a}$ Department of Nuclear Medicine, Peking University First Hospital, Beijing, 100034, China. E-mail: yangxing2017@bjmu.edu.cn

${ }^{b}$ State Key Laboratory of Organic-Inorganic Composites, Beijing University of Chemical Technology, 15 Beisanhuan East Road, Chaoyang District, Beijing 100029, China 'State Key Laboratory of Elemento-Organic Chemistry, Department of Chemical Biology, National Pesticide Engineering Research Center (Tianjin), Nankai University, Tianjin, 300071, China. E-mail: zhenxi@nankai.edu.cn; Tel: +86 22 23504782

${ }^{d}$ Collaborative Innovation Center of Chemical Science and Engineering (Tianjin), China

${ }^{e}$ Peking University School of Medical Technology, Beijing, 100191, China

$\dagger$ Electronic supplementary information (ESI) available: Experimental procedures and additional figures. See DOI: 10.1039/c8ra09303b

$\$$ The authors pay equal contributions to this work.
}

We have been interested in the development of fast chemoselective reactions for bioconjugations. ${ }^{12}$ We reported $o, o^{\prime}$ difluorinated aromatic azide can accelerate both the reaction rate significantly on SPAAC and $\mathrm{H}_{2} \mathrm{~S}$-mediated reduction of the azide. ${ }^{12 c}$ Therefore, we envision that multi-fluorinated aromatic azide may have interesting properties for fast and convenient bifunctional conjugation. 4-Azido-2,3,5,6-tetrafluorobenzoic acid (1) was selected for investigation. Here, we report the SPAAC kinetic properties of $\mathbf{1}$ and its applications for protein labelling in vitro and for bioimaging of subcellular organelles in living cells (Fig. 1).

To test our idea, the reaction between 1 and $[1 R, 8 R, 9 S]$ bicyclo[6.1.0]non-4-yn-9-yl methanol (2) was studied for SPAAC reaction, monitored with time-dependent ${ }^{1} \mathrm{H}$ NMR. To our delight, the reaction could finish within $5 \mathrm{~min}$. As shown in Fig. 2, the ${ }^{1} \mathrm{H}-\mathrm{NMR}$ signal of $2(40 \mathrm{mM})$ completely changed to the product (3) after adding $\mathbf{1}$ for $5 \mathrm{~min}$, and there's no further change at $15 \mathrm{~min}$ and 2 hours in NMR spectra. The resulted

(a) Our previous work

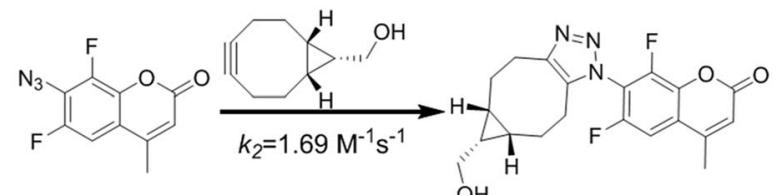

(b) The design

$\mathrm{OH}$

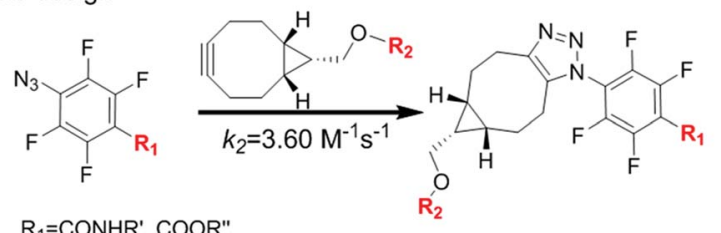

Fig. 1 Rational design of SPAAC reaction based on multi-fluorinated aromatic azide. (a) SPAAC reaction based on $0, O^{\prime}$-difluorinated aromatic azide reported in our previous work; (b) SPAAC reaction based on tetra-fluorinated aromatic azide for faster and bifunctional ligation. 

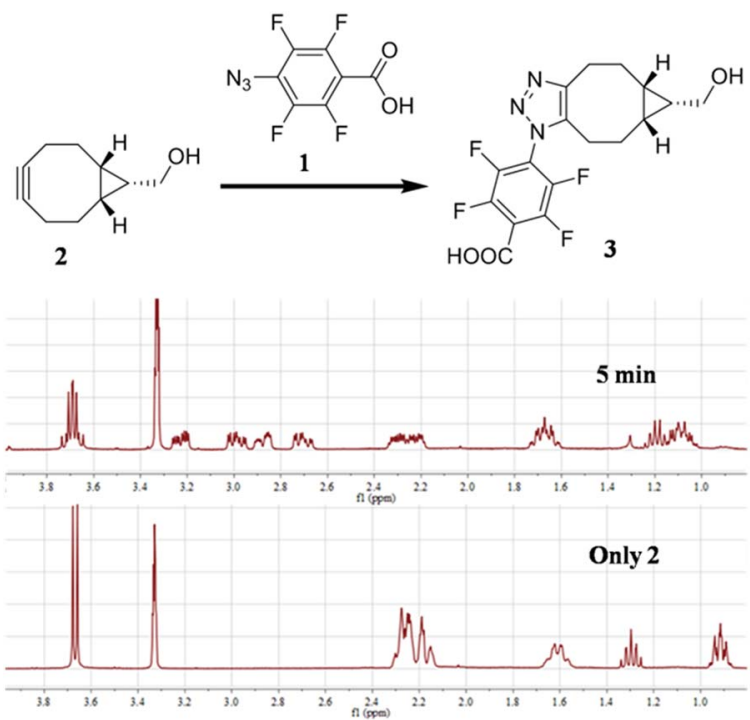

Fig. $2{ }^{1} \mathrm{H}$ NMR analysis of the reaction between $1(120 \mathrm{mM})$ and 2 (40 $\mathrm{mM})$. The reaction was carried out in $\mathrm{CD}_{3} \mathrm{OD}$.

product was also confirmed by high resolution mass spectrum. This result implies that the 4-azido-2,3,5,6-tetrafluorobenzoic acid derivatives can be used for this fast SPAAC reaction. But NMR is limited by its relative low sensitivity for accurate testing the kinetic rate at micromolar concentration.

In order to quantify the kinetic rate, we designed a procedure based on fluorescence resonance energy transfer (FRET) method to monitor this fast SPAAC reaction. We synthesized the azide compound $\mathbf{4}$ conjugated to an azo-quencher and the cyclooctyne compound 5 conjugated to a BODIPY-dye (Fig. 3). All the compounds were isolated and characterized by NMR and (a)

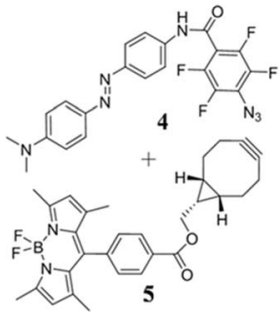

(b)

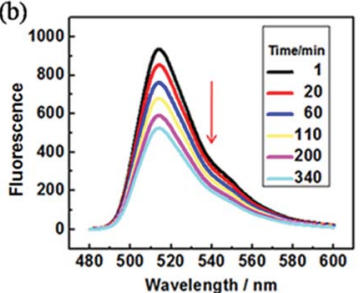

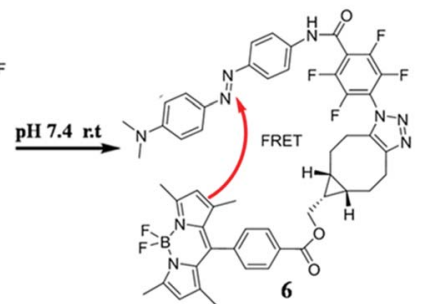

(c)

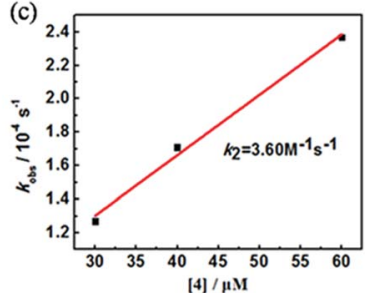

Fig. 3 (a) Chemical structures of 4 and 5 and their SPAAC reaction to produce 6 . (b) Time-dependent fluorescence spectra of $5(2 \mu \mathrm{M})$ upon treated with $4(30 \mu \mathrm{M})$ in PBS $\left(50 \mathrm{mM}, \mathrm{pH} 7.4\right.$, containing $\left.70 \% \mathrm{CH}_{3} \mathrm{CN}\right)$ at room temperature (excitation, $473 \mathrm{~nm}$ ). The reaction time is shown inset. (c) The linear relationship between the concentration of 4 and $k_{\text {obs }}$. The slope of the best linear fitting gives the reaction rate $k_{2}\left(\mathrm{M}^{-1}\right.$ $\mathrm{s}^{-1}$.
HRMS. After the reaction between $\mathbf{4}$ and 5, $\mathbf{6}$ could formed in which BODIPY fluorescent signal was quenched due to the FRET effect. Such fluorescence change could be employed to monitor the reaction in a real-time.

The reaction between $\mathbf{4}$ and $\mathbf{5}$ was set up in PBS buffer $(2 \mu \mathrm{M}$ 5, $50 \mathrm{mM}, \mathrm{pH} 7.4$ ) and the maximum emission at $511 \mathrm{~nm}$ was monitored with the excitation at $473 \mathrm{~nm}$. The pseudo-first-order rate $k_{\text {obs }}$ was determined by fitting the data with a single exponential function. The linear fitting between $k_{\mathrm{obs}}$ and the concentrations of 4 gave the reaction rate $\left(k_{2}\right)$ as $3.60 \mathrm{M}^{-1} \mathrm{~s}^{-1}$. It's two-fold faster than $o, o^{\prime}$-difluorinated aromatic azide that we reported earlier, 1500-fold faster than the original SPAAC reaction and among the fastest SPAAC reactions reported so far.

With this highly efficient reaction, covalent protein labelling was first tested as its application. $N$-Hydroxysuccinimide ester of 4-azido-2,3,5,6-tetrafluorobenzoic acid was synthesized as bifunctional labelling compound (7) for amide and SPAAC reactions. We chose bovine serum albumin (BSA) and lysozyme as model proteins considering their different sizes and functions. ${ }^{8}$ As shown in Fig. 4a, we tested to label protein first with 7 and then conjugated a dye to the protein using fluorescent cyclooctyne (5). BSA or lysozyme was treated with $0.5 \mathrm{mM} 7$ in PBS buffer (50 mM, pH 8.5, containing 10\% DMSO) for $2 \mathrm{~h}$ to incorporate tetra-fluorinated aromatic azide into the protein. After removing of small molecules, the azide labelled protein was incubated with $1 \mathrm{mM} 5$ for another $2 \mathrm{~h}$ to achieve SPAAC protein fluorescent dye labelling. As a control, the azide labelled protein was also treated with $\mathrm{Na}_{2} \mathrm{~S}$ for 10 minutes to reduce azide into amine before incubating with 5 , so to prove the reaction specificity. The labelled proteins were analysed with SDS-PAGE either stained by Coomassie blue or excited under UV lamp to visualize the desired protein. The results are shown in Fig. 4b. The strong fluorescent labelled BSA (lane 1) and

(a)
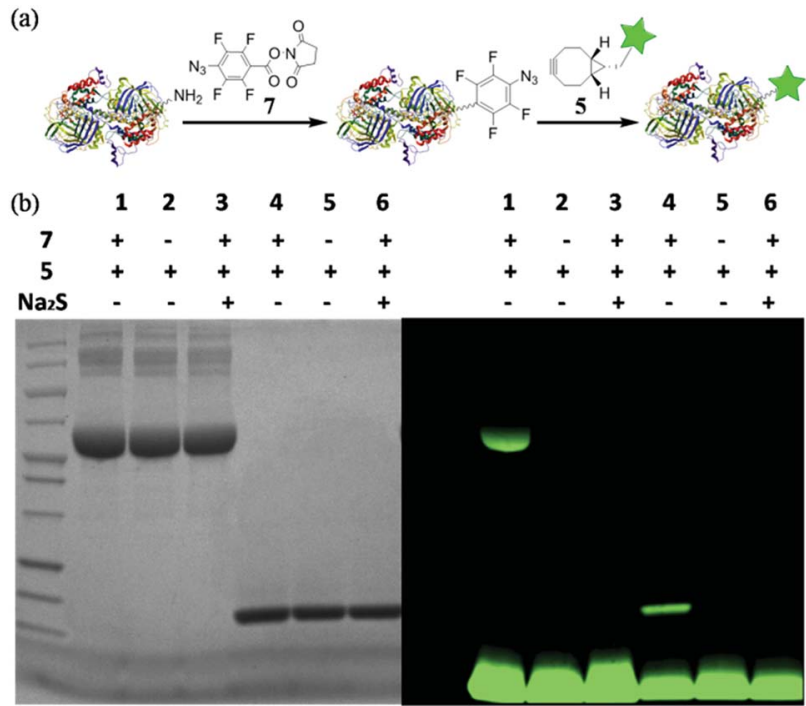

Fig. 4 Fluorescence labeling of BSA and lysozyme via the SPAAC reaction. (a) The fluorescence labelling strategy. (b) 15\% SDS-PAGE of BSA (lane 1-3) and lysozyme (lane 4-6) was imaged under UV lamp (right) and then stained by Coomassie blue (left). 
lysozyme (lane 4) could be observed after the reaction with tandem addition of 7 and 5 , while the controls of 5 only (lane 2 and 5) and $\mathrm{Na}_{2} \mathrm{~S}$ treated labelling (lane 3 and 6) did not show any fluorescent signal. The results indicated that tetrafluorinated aromatic azide-cyclooctyne is a highly efficient SPAAC reaction for protein labelling.

To future explore the biocompatibility of this SPAAC reaction in living cells, we tested it for bioimaging of the subcellular organelle mitochondria. Triphenylphosphines are known to enrich into mitochondria mainly due to its positive charged character. ${ }^{13}$ We designed and synthesized compound $\mathbf{8}$, with the azide conjugated to a triphenylphosphine. Upon incubating 8 with the cells, we expected it would target mitochondria, so we can use SPAAC reaction to label the cells with fluorescent compound 5 (Fig. 5a). Human embryonic kidney cells 293 (HEK 293) were chosen for the experiment. The cells were first treated with $8(10 \mu \mathrm{M})$ for $20 \mathrm{~min}$ to accumulate tetra-fluorinated aromatic azide into mitochondria, and then incubated with 5 $\mu \mathrm{M} 5$ for another $30 \mathrm{~min}$. After the non-specific fluorescent signal was washed away, the cells were imaged under the

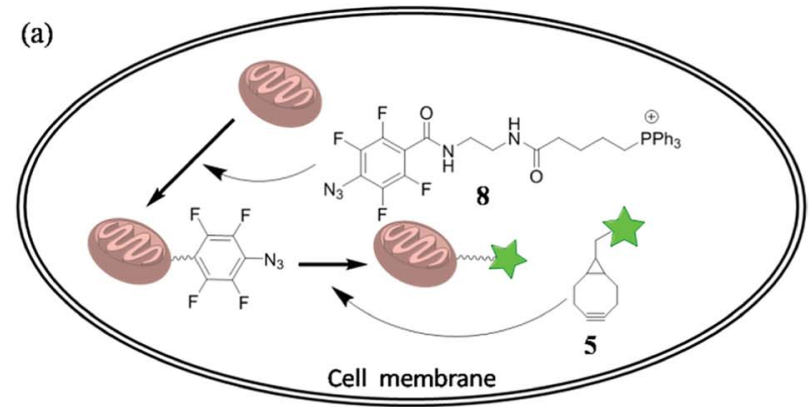

(b)
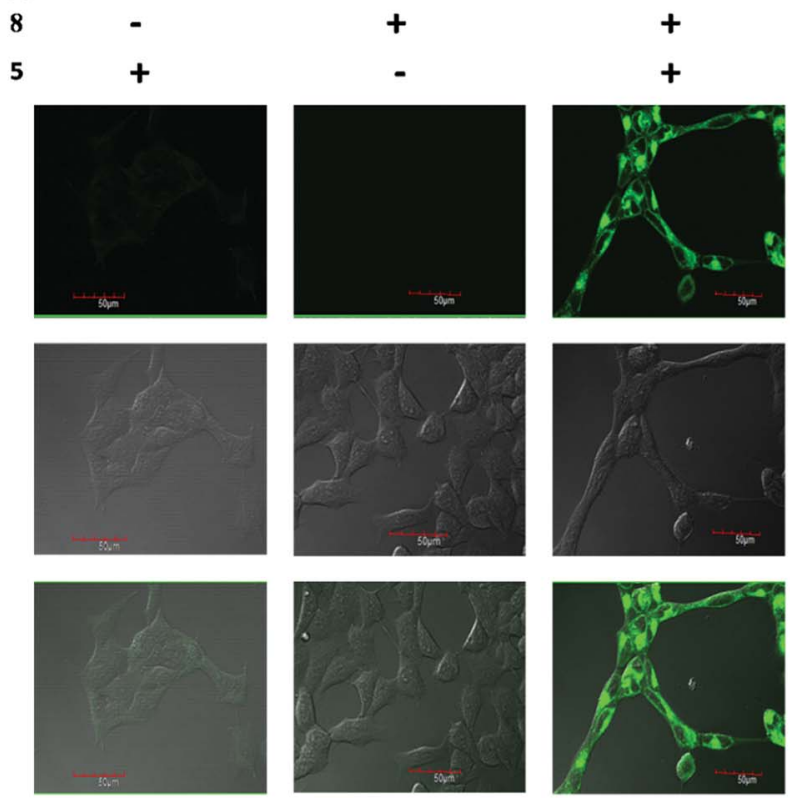

Fig. 5 Fluorescence labelling of mitochondria in living cells via the SPAAC reaction. (a) The fluorescence labelling strategy. (b) Fluorescence images of HEK293 cells. HEK293 cells were treated for 30 min only with $10 \mu \mathrm{M}$ of 5 (left); 20 min only with $10 \mu \mathrm{M}$ of 8 (middle); $20 \mathrm{~min}$ with $10 \mu \mathrm{M}$ of 8 followed by $5 \mu \mathrm{M}$ of 5 for 30 min (right). excitation of $488 \mathrm{~nm}$. The experimental conditions and results were shown in Fig. 5b. The cells could only be fluorescencelabelled when treated with both $\mathbf{8}$ and $\mathbf{5}$, and the imaging signal all localized on mitochondria. The result proved both the feasibility and biocompatibility for the application of this improved SPAAC conjugation at cellular level. Its superior kinetic character $\left(k_{2}\right.$ of $\left.3.60 \mathrm{M}^{-1} \mathrm{~s}^{-1}\right)$ may even enable in vivo applications for pretargeted imaging, ${ }^{\mathbf{1 4}}$ which is currently under investigation.

\section{Conclusions}

In summary, we investigated tetra-fluorinated aromatic azide for SPAAC reactions with cyclooctyne. The reaction rate could reach $3.60 \mathrm{M}^{-1} \mathrm{~s}^{-1}$ for 4 and 5, which is among the fastest SPAAC reactions reported so far. The commercially available agent 4-azido-2,3,5,6-tetrafluorobenzoic acid (1) enables its convenient application as bifunctional biorthogonal tool. We have successfully employed the reaction for covalent labelling of proteins and the mitochondria in living cell. In vivo applications are currently under investigation.

\section{Conflicts of interest}

There are no conflicts to declare.

\section{Acknowledgements}

This work was supported by the MOST (2017YFD0200900), NSFC (21572019, 21877008), 111 project (B14004), National Thousand Young Talents Program.

\section{Notes and references}

1 (a) C. P. R. Hackenberger and D. Schwarze, Angew. Chem., Int. Ed., 2008, 47, 10030; (b) D. Schumacher, J. Helma, A. F. L. Schneider, H. Leonhardt and C. P. R. Hackenberger, Angew. Chem., Int. Ed., 2018, 57, 2314; (c) C. Witte, V. Martos, H. M. Rose, S. Reinke, S. Klippel, L. Schrçder and C. P. R. Hackenberger, Angew. Chem., Int. Ed., 2015, 54, 2806.

2 (a) S. V. Orski, A. A. Poloukhtine, S. Arumugam, L. D. Mao, V. V. Popik and J. Locklin, J. Am. Chem. Soc., 2010, 132, 11024; (b) W. Luo, P. Gobbo, C. D. McNitt, D. A. Sutton, V. V. Popik and M. S. Workentin, Chem.-Eur. J., 2017, 23, 1052; (c) C. A. DeForest and K. S. Anseth, Nat. Chem., 2011, 3, 925.

3 (a) A. Wurzer, C. Seidl, A. Morgenstern, F. Bruchertseifer, M. Schwaiger, H.-J. Wester and J. Notni, Chem.-Eur. J., 2018, 24, 547; (b) Z. Zhou, S. K. Chitneni, N. Devoogdt, M. R. Zalutsky and G. Vaidyanathan, Bioorg. Med. Chem., 2018, 26, 1939; (c) A. Wurzer, J. Pollmann, A. Schmidt, D. Reich, H.-J. Wester and J. Notni, Mol. Pharm., 2018, 15, 4296.

4 H. C. Kolb, M. G. Finn and K. B. Sharpless, Angew. Chem., Int. Ed., 2001, 40, 2004. 
5 (a) V. V. Rostovtsev, L. G. Green, V. V. Fokin and K. B. Sharpless, Angew. Chem., Int. Ed., 2002, 41, 2596; (b) C. W. Tornoe, C. Christensen and M. Meldal, J. Org. Chem., 2002, 67, 3057.

6 N. J. Agard, J. A. Prescher and C. R. Bertozzi, J. Am. Chem. Soc., 2004, 126, 15046.

7 G. Wittig and A. Krebs, Chem. Ber., 1961, 94, 3260.

8 G. S. McKay and M. G. Finn, Chem. Biol., 2014, 21, 1075.

9 (a) J. Dommerholt, S. Schmidt, R. Temming, L. J. A. Hendriks, F. P. J. T. Rutjes, J. C. M. van Hest, D. J. Lefeber, P. Friedl and F. L. van Delft, Angew. Chem., Int. Ed., 2010, 49, 9422; (b) J. M. Baskin, J. A. Prescher, S. T. Laughlin, N. J. Agard, P. V. Chang, I. A. Miller, A. Lo, J. A. Codelli and C. R. Bertozzi, Proc. Natl. Acad. Sci. U. S. A., 2007, 104, 16793; (c) N. J. Agard, J. M. Baskin, J. A. Prescher, A. Lo and C. R. Bertozzi, ACS Chem. Biol., 2006, 1, 644.

10 (a) X. Ning, J. Guo, M. A. Wolfert and G.-J. Boons, Angew. Chem., Int. Ed., 2008, 47, 2253; (b) J. C. Jewett, E. M. Sletten and C. R. Bertozzi, J. Am. Chem. Soc., 2010, 132, 3688; (c) M. F. Debets, S. S. van Berkel, S. Schoffelen, F. P. J. T. Rutjes, J. C. M. van Hest and F. L. van Delft, Chem. Commun., 2010, 46, 97; (d) A. Kuzmin, A. Poloukhtine, M. A. Wolfert and V. V. Popik, Bioconjugate Chem., 2010, 21, 2076.

11 J. Dommerholt, O. van Rooijen, A. Borrmann, C. F. Guerra, F. M. Bickelhaupt and F. L. van Delft, Nat. Commun., 2014, 5, 5378.

12 (a) Y. Xie, L. Cheng, Y. Gao, X. Cai, X. Yang, L. Yi and Z. Xi, Chem.-Asian J., 2018, 13, 1791; (b) D. Ma, Y. Xie, J. Zhang, D. Ouyang, L. Yi and Z. Xi, Chem. Commun., 2014, 50, 15581; (c) J. Zhang, Y. Gao, X. Kang, Z. Zhu, Z. Wang, Z. Xi and L. Yi, Org. Biomol. Chem., 2017, 15, 4212.

13 N. K. Roopa, V. Bhalla and M. Kumar, Chem. Commun., 2015, 51, 15614.

14 J.-P. Meyer, P. Adumeau, J. S. Lewis and B. M. Zeglis, Bioconjugate Chem., 2016, 27, 2791. 